\title{
EVALUATION OF HYPERHOMOCYSTEINAEMIA AS A RISK FACTOR FOR ISCHAEMIC HEART DISEASE IN YOUNG POPULATION
}

\author{
Gauri Malhar Nilajkar1, Anar Viraj Khandeparkar², Rukma Jagannath Kolwalkar ${ }^{3}$ \\ ${ }_{1}^{1}$ Lecturer, Department of Medicine, Goa Medical College, Bambolim, Goa, India. \\ ${ }^{2}$ Associate Professor, Department of Medicine, Goa Medical College, Bambolim, Goa, India. \\ ${ }^{3}$ Lecturer, Department of Medicine, Goa Medical College, Bambolim, Goa, India.
}

\begin{abstract}
\section{BACKGROUND}

Cardiovascular diseases are leading causes of mortality and morbidity in today's world. Numerous studies have evaluated a spectrum of both modifiable and non-modifiable risk factors of CVD in the young population. Among them homocysteine is novel and plays a role in increasing oxidative stress, thrombogenicity and endothelial dysfunction.

The purpose of the present study was to evaluate plasma homocysteine levels in young Goans $\leq 45$ years of age, presenting with acute coronary syndrome and to assess the role of hyperhomocysteinaemia and its relationship with other conventional risk factors for coronary artery disease.
\end{abstract}

\section{MATERIALS AND METHODS}

Case and Control groups were studied for clinical characteristics and risk factors using health assessment questionnaire and lab investigations, which included homocysteine levels.

Settings and Design- This was a retrospective, observational, case-control study conducted at Goa Medical College, Bambolim, a tertiary care institute, over a period of one year and included 60 young patients, $\leq 45$ years of age of which 40 were cases presenting with acute coronary syndrome and 20 were similar controls without evidence of IHD according to the inclusion and exclusion criteria.

\section{RESULTS}

It was observed that mean serum Homocysteine level was $20.32 \pm 1.36 \mu \mathrm{mol} / \mathrm{L}$ in the case group and $12.92 \pm 0.63 \mu \mathrm{mol} / \mathrm{L}$ in the control group. By statistical analysis, it was deducted that a significant correlation exists between high serum homocysteine levels and the risk of developing premature coronary artery disease with odds ratio of 27.968 and highly significant p-value. High homocysteine levels were observed in majority of cases who were obese, hypertensive, diabetic or smokers and those with dyslipidaemias in comparison with controls.

\section{CONCLUSION}

The study concluded that hyperhomocysteinaemia is a risk factor for premature CAD in young Goan patients with acute coronary syndrome. The study also showed that smoking, dyslipidaemia, diabetes mellitus and hypertension are associated with hyperhomocysteinaemia.

\section{KEY WORDS}

Homocysteine, Hyperhomocysteinaemia, Nutrition, Atherosclerosis, Risk Factors, Dyslipidaemia, Methionine Metabolism. HOW TO CITE THIS ARTICLE: Nilajkar GM, Khandeparkar AV, Kolwalkar RJ. Evaluation of hyperhomocysteinaemia as a risk factor for ischaemic heart disease in young population. J. Evolution Med. Dent. Sci. 2018;7(43):4668-4674, DOI: $10.14260 /$ jemds/2018/1041

\section{BACKGROUND}

The incidence of CVD is on a dramatic rise due to changes in lifestyle and food choices, especially in the younger population. A study of Indian patients undergoing angiography has shown that in about one-third of the patients, no major known risk factors are detectable. Therefore, there is a renewed interest in the role of novel risk factors. Since its discovery in 1932, Homocysteine has been under speculation regarding its role in increasing risk of CVD.

'Financial or Other Competing Interest': None.

Submission 03-09-2018, Peer Review 02-10-2018,

Acceptance 09-10-2018, Published 22-10-2018.

Corresponding Author:

Dr. Gauri Malhar Nilajkar,

Department of Medicine,

Faculty Block,

Goa Medical College,

Bambolim-403202, Goa, India.

E-mail: gaurinilajkar@gmail.com

DOI: $10.14260 /$ jemds/2018/1041 folate, vitamin B6 and vitamin B12 affect enzyme-mediated transmethylation and transsulfuration metabolic pathways resulting in hyperhomocysteinaemia which leads to oxidative stress and promotes atherogenesis which is a major pathogenic factor for cardiovascular disease.

Homocysteine is a sulfhydryl containing amino acid and an intermediate product of normal biosynthesis of amino acids, methionine and cysteine. It is produced via demethylation of dietary methionine. It occurs in plasma in four forms: 1\% free thiol, 70 - 80\% disulphide bound to plasma proteins, mainly albumin and $20-30 \%$ combines with itself to form the dimer, homocysteine or with other thiols.[1] The term total serum homocysteine refers to the combined pool of all four forms of homocysteine.[4]

The first step in synthesis of homocysteine is the formation of S-adenosylmethionine (SAM) which is a methyl donor from methionine. SAM is then converted to Sadenosylhomocysteine (SAH), which is further hydrolysed to yield homocysteine and adenosine. 
Depending on whether there is a relative excess or a deficiency of methionine, homocysteine may then enter either transsulfuration or remethylation pathways. [5]

Remethylation occurs under conditions of low protein intake, where homocysteine is metabolised primarily via one of the two methionine conserving pathways, in the liver by betaine as methyl donor and in other tissues by folate derived, N5 $\mathrm{N}^{10}$ methylenetetrahydrofolate by enzyme MTHFR and methionine synthase with Vitamin B12 as essential co-factor.[6]

When the remethylation pathway is saturated, homocysteine is converted to cystathionine (And then cysteine) by cystathionine $\beta$-synthase (C $\beta S$ ) with Vitamin B6 as essential co-factor by transsulfuration. Cysteine is further metabolised to sulphate and excreted in the urine.[6] Thus, based on either relative excess or deficiency of methionine, homocysteine may enter either transsulfuration or remethylation pathways. Abnormalities of these pathways, as a result of nutrient deficiencies or enzyme inactivity may result in accumulation of homocysteine. ${ }^{[5]}$

Hyperhomocysteinaemia is defined as a medical condition characterised by an abnormally high level (above $15 \mu \mathrm{mol} / \mathrm{L})$ of homocysteine in the blood.[2,3] Total homocysteine concentration in plasma of healthy humans (fasting) is low and its level is between 5.0 and $15.0 \mu \mathrm{mol} / \mathrm{L}$ when assessed with the use of HPLC, 5.0 - $12.0 \mu \mathrm{mol} / \mathrm{L}$ when immunoassay methods are used. When the level is between $16-30 \mu \mathrm{mol} / \mathrm{L}$ it is classified moderate, $31-100 \mu \mathrm{mol} / \mathrm{L}$ as intermediate and a value above $100 \mu \mathrm{mol} / \mathrm{L}$ is classified as severe hyperhomocysteinaemia.

There are two types of hyperhomocysteinaemia: (a) The rare but severe forms are due to major genetic mutations of the enzymes implicated in homocysteine metabolism; (b) The more common forms cause moderately elevated homocysteine levels related to a pathogenesis such as genetic and environmental factors. ${ }^{[3]}$

Hyperhomocysteinaemia can arise from genetic enzyme defects in homocysteine metabolism. The enzymes involved are 5, 10-methylenetetrahydrofolate reductase, methionine synthase and cystathionine- $\beta$-synthase. Single nucleotide polymorphism of 5,10 -methylenetetrahydrofolate reductase which is associated with mild (13 - $24 \mu \mathrm{mol} / \mathrm{L})$ and moderate (25 - $60 \mu \mathrm{mol} / \mathrm{L}$ ) hyperhomocysteinaemia is most common worldwide.[7]

The most common genetic cause of severe hyperhomocysteinaemia and classic homocystinuria (Congenital homocystinuria) is homozygous deficiency of C $\beta S$ (Cystathionine- $\beta$-synthase).

Hyperhomocysteinaemia can also arise from nutritional deficiencies of folate, vitamin $\mathrm{B}_{6}$ and vitamin $\mathrm{B}_{12}{ }^{[7,8]}$ These cofactor levels are inversely related to total homocysteine deficiency leading increased risk of hyperhomocysteinaemia.[7,8,9] Immune disorders, cancer, psoriasis, thyroid illness and diabetes along with several drugs, alcohol, tobacco, coffee, older age and menopause are seen to be associated with moderately elevated homocysteine levels. As homocysteine is cleared from plasma by the kidneys, renal dysfunction can increase levels. Homocysteine can be increased by various drugs and diseases that interfere with folate, vitamin $\mathrm{B}_{6}$ and $\mathrm{B}_{12}$ metabolism. ${ }^{8]}$ Increased levels are seen with use of Colestipol, Cholestyramine, metformin, Methotrexate, Anticonvulsants, Levodopa, Niacin, theophylline, Cyclosporine and fibrates. Decreased levels occur with use of Penicillamine, $\mathrm{N}$-acetyl cysteine and Betaine.

Plasma homocysteine increases with advancing age in both sexes. Premenopausal women have lower homocysteine compared with post-menopausal women and men of similar age. These age-related and gender-related differences may be due to differing nutrient intake and vitamin requirements for homocysteine metabolism.[10,11]

Physical activity lowers plasma homocysteine. Alcohol intake has variable effect on homocysteine. Long term alcohol abuse may increase plasma homocysteine due to malnutrition associated B Vitamin depletion. Moderate alcohol consumption may be associated with lower homocysteine.[10,11]

In diabetics, homocysteine may be normal or low because of glomerular hyperfiltration. The onset of vascular disease or falling glomerular filtration rate can cause levels to rise and increase the risk of microalbuminuria.[12]

Homocysteine can mediate pathogenesis of CVD by several different mechanisms such as adverse effects on vascular endothelium and smooth muscle cells with alterations of arterial structure and function. Some of the presumed mechanisms include increase in proliferation of vascular smooth muscle cells, endothelial dysfunction, oxidative damage, collagen synthesis and deterioration of arterial wall elastic tissue.[13]

Endothelium dependent vasodilation is impaired in the hyperhomocysteinaemics, presumably due to reduced bioavailability of NO and alteration of redox potential of aminothiols may affect extracellular antioxidant defense mechanisms.[13]

Homocysteine is capable of initiating an inflammatory response in vascular smooth muscle cells by stimulating CRP production.[14]

The prevalence of hyperhomocysteinaemia is estimated as $5 \%$ of general population and $13-47 \%$ among patients with symptomatic atherosclerotic vascular disease.[8] More than $90 \%$ of patients respond to multivitamin treatment within 2 - 6 weeks irrespective of the cause.[8] Use of vitamins is associated with lowered risk of vascular disease in general population.[15]

Folate supplementation is the major therapeutic intervention for the treatment of hyperhomocysteinaemia. Folic acid therapy alone or combined with vitamin B6 and $\mathrm{B} 12$, reduces homocysteine even in patients who are not vitamin deficient. Several studies have demonstrated that 0.65 to $10 \mathrm{mg}$ folic acid per day alone and together with Vit B12 and vitamin B6 reduce the fasting and post methionine load plasma homocysteine levels by $25-50 \%$, both in healthy subjects and those with vascular disease.[16]

However, in B12 deficiency patients, supplementation brings about marked reduction in homocysteine concentration. Combination therapy with different vitamins is needed to achieve adequate suppression of homocysteine in many patients.[16]

\section{MATERIALS AND METHODS}

This was a retrospective observational case-control study conducted at Goa Medical College, Bambolim, a tertiary care institute over a period of one year and included 60 young patients, $\leq 45$ years of age, of which 40 were cases presenting 
with acute coronary syndrome and 20 were similar controls without evidence of IHD according to the inclusion and exclusion criteria.

Inclusion criteria were young $\leq 45$ years of age, presenting with first incidence of acute coronary syndrome documented by ECG/ Cardiac enzymes to CCU.

Known malignancy, hypothyroidism, connective tissue disorder, psoriasis, renal disease and IHD in the past were exclusion criteria. Also, those on medications such as multivitamins, oestrogens, metformin, folate antagonists, anticonvulsants and anti-lipid agents were excluded from the study.

Patients presenting with chest pain, which was proven to be non-cardiac with normal ECG and cardiac enzymes, but satisfying the inclusion and exclusion criteria formed the control population.

Study population consisted of 40 patients (35 males/ 5 females) with age range of 26-45 years. Cases were defined with confirmed diagnosis of ACS who satisfied inclusion criteria. Control population had 20 patients (18 males/ 2 females) with age range of 34 - 44 years. Control was defined as presentation with non-cardiac chest pain and with normal ECG and cardiac enzymes.

For the cases ACS was sub-classified as STEMI, NSTEMI and Unstable Angina based on ECG and biomarkers. Health status and lifestyle patterns were assessed using a detailed questionnaire which included illness, medications and addictions.

Standard criteria were used for diagnosis of hypertension, diabetes mellitus, dyslipidaemia and obesity. Smoking was defined as more than 10 cigarettes or beedis daily at least for 2 years. Alcohol abuse was quantified as regular intake of $>21$ units/ week for males and $>14$ units per week for females for at least one year prior.

Cases and controls were subjected to blood sampling before intervention. Homocysteine concentration in plasma was measured using chemiluminescence method (Diagnostic Products Corporation, USA) in same laboratory. Process involves pre-treatment and hydrolysis releasing Homocysteine from binding proteins, incubation with labelled antibodies and measurement of chemiluminescence generated after substrate addition.

By statistical analysis, all results were reported as Mean \pm SEM. The Mean and SD values for homocysteine and other variables was calculated.

The student's ' $\mathrm{T}$ ' test for unpaired values was used to compare continuous variables between the different groups. The Chi-square test was used to calculate the differences in discrete variables between the various groups. Multivariate odds were calculated by multiple logistic regression analysis on SPSS (version 10).

\section{RESULTS}

Mean BMI among Cases was marginally higher $(22.83 \pm 2.64)$ compared to Controls $(21.98 \pm 2.52)$. Overall $36.7 \%$ of the patients were smokers, $25 \%$ cases $(10 / 40)$ and $60 \%$ controls $(12 / 20) .17 .5 \%$ cases $(7 / 40)$ and $45 \%$ controls $(9 / 20)$ had history of regular intake of alcohol.

$7.5 \%$ cases $(3 / 40)$ and $30 \%$ controls $(6 / 20)$ were hypertensives. $17.5 \%$ cases $(7 / 40)$ and $10 \%$ controls $(2 / 20)$ were diabetics.
In both the groups, majority patients were middle socioeconomic class which constituted $80 \%$ of total.

Majority of patients of both groups had moderate lifestyle habits. Among cases $17.5 \%(7 / 40)$ led a sedentary lifestyle, while $22.5 \%$ (9/40) complained of severe stressors. 85\% cases $(34 / 40)$ were non-vegetarians, while $15 \%(6 / 40)$ were pure vegetarians. This distribution is comparable to the control group, where $10 \%(2 / 20)$ were pure vegetarians and remainder had mixed dietary preferences.

\begin{tabular}{|c|c|c|c|c|c|}
\hline \multirow{2}{*}{\multicolumn{2}{|c|}{ Lipid Profile }} & & \multicolumn{2}{|c|}{ Group } & \multirow{2}{*}{ Total } \\
\hline & & & \multirow{2}{*}{\begin{tabular}{|c|}
$\begin{array}{c}\text { Cases }(\mathrm{N}= \\
\mathbf{4 0})\end{array}$ \\
$5(12.5 \%)$ \\
\end{tabular}} & \multirow{2}{*}{$\begin{array}{c}\begin{array}{c}\text { Controls } \\
(\mathbf{N}=\mathbf{2 0})\end{array} \\
0(0 \%) \\
\end{array}$} & \\
\hline & \multirow{3}{*}{$\begin{array}{c}\text { Total } \\
\text { cholesterol }\end{array}$} & $\mathrm{BH}$ & & & $5(8.3 \%)$ \\
\hline 1 & & $\mathrm{H}$ & $6(15 \%)$ & $7(35 \%)$ & $13(21.7 \%)$ \\
\hline & & $\mathrm{N}$ & $29(72.5 \%)$ & $13(65 \%)$ & $42(70 \%)$ \\
\hline \multirow{2}{*}{2} & \multirow{2}{*}{ Triglycerides } & $\mathrm{H}$ & $9(22.5 \%)$ & $5(25 \%)$ & $14(23.3 \%)$ \\
\hline & & $\mathrm{N}$ & $31(77.5 \%)$ & $15(75 \%)$ & $46(76.7 \%)$ \\
\hline \multirow{2}{*}{3} & \multirow{2}{*}{ VLDL } & $\mathrm{H}$ & $0(0 \%)$ & $0(0 \%)$ & $0(0 \%)$ \\
\hline & & $\mathrm{N}$ & $40(100 \%)$ & $20(100 \%)$ & $60(100 \%)$ \\
\hline \multirow{3}{*}{4} & \multirow{3}{*}{ HDL } & $\mathrm{H}$ & $0(0 \%)$ & $1(5 \%)$ & $1(1.7 \%)$ \\
\hline & & $\mathrm{L}$ & $16(40 \%)$ & $7(35 \%)$ & $23(38.3 \%)$ \\
\hline & & $\mathrm{N}$ & $24(60 \%)$ & $12(60 \%)$ & $36(60 \%)$ \\
\hline \multirow{2}{*}{5} & \multirow{2}{*}{ LDL } & $\mathrm{H}$ & $14(35 \%)$ & $12(60 \%)$ & $26(43.3 \%)$ \\
\hline & & $\mathrm{N}$ & $26(65 \%)$ & $8(40 \%)$ & $34(56.7 \%)$ \\
\hline
\end{tabular}

$27.5 \%$ cases and 7\% controls had above normal serum cholesterol values and $22.5 \%$ cases and $25 \%$ controls had hypertriglyceridaemia. HDL values were low in around $40 \%$ of cases as well as controls.

\begin{tabular}{|c|c|c|c|c|c|}
\hline & Group & N & Mean & $\begin{array}{c}\text { Std. } \\
\text { Deviation }\end{array}$ & $\begin{array}{c}\text { Std. } \\
\text { Error } \\
\text { Mean }\end{array}$ \\
\hline \multirow{2}{*}{$\begin{array}{c}\text { Total } \\
\text { Cholesterol }\end{array}$} & Case & 40 & 181.15 & 45.306 & 7.163 \\
\hline \multirow{2}{*}{ TG } & Control & 20 & 202.45 & 80.219 & 17.938 \\
\cline { 2 - 6 } & Control & 20 & 155.48 & 54.779 & 8.661 \\
\hline \multirow{2}{*}{ VLDL } & Case & 40 & 31.07 & 10.591 & 1.675 \\
\cline { 2 - 6 } & Control & 20 & 33.10 & 14.542 & 3.252 \\
\hline \multirow{2}{*}{ HDL } & Case & 40 & 40.63 & 8.381 & 1.325 \\
\cline { 2 - 6 } & Control & 20 & 43.0 & 12.230 & 2.735 \\
\hline \multirow{2}{*}{ LDL } & Case & 40 & 120.13 & 46.314 & 7.323 \\
\cline { 2 - 6 } & Control & 20 & 112.52 & 46.36 & 10.366 \\
\hline
\end{tabular}

Mean FBSL among cases was $104.35 \pm 3.97 \mathrm{mg} \%$ and PPBSL was $131.55 \pm 5.84 \mathrm{mg} \%$.

Mean FBSL among controls was $112.00 \pm 5.21 \mathrm{mg} \%$ and PPBSL was $146.25 \pm 7.52 \mathrm{mg} \%$.

\section{Homocysteine Distribution}

\begin{tabular}{|c|c|c|c|}
\hline \multirow{2}{*}{} & \multicolumn{2}{|c|}{ Group } & \multirow{2}{*}{ Total } \\
\cline { 2 - 3 } & Case & Control & \\
\hline $\mathrm{H}$ & $30(75 \%)$ & $3(15 \%)$ & $33(55 \%)$ \\
\hline $\mathrm{N}$ & $10(25 \%)$ & $17(85 \%)$ & $27(45 \%)$ \\
\hline
\end{tabular}




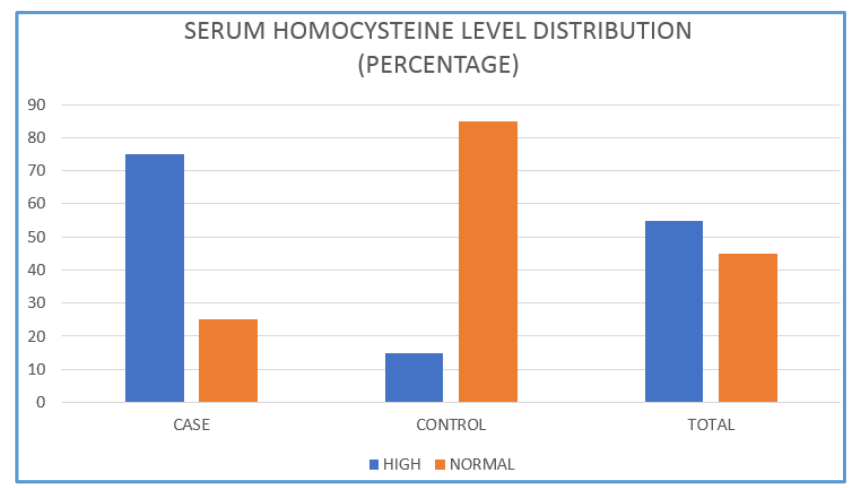

\begin{tabular}{|c|c|c|c|c|c|}
\hline & Group & N & Mean & $\begin{array}{c}\text { Standard } \\
\text { Deviation }\end{array}$ & $\begin{array}{c}\text { Std. Mean } \\
\text { Error }\end{array}$ \\
\hline $\begin{array}{c}\text { Serum } \\
\text { Homocysteine } \\
\text { Level }\end{array}$ & Case & 40 & 20.319 & 8.620 & 1.3629 \\
\cline { 2 - 6 } & Control & 20 & 12.920 & 2.827 & 0.6321 \\
\hline
\end{tabular}

Mean serum Homocysteine level was $20.32 \pm 1.36$ $\mathrm{mmol} / \mathrm{L}$ in the case group compared to $12.92 \pm 0.63 \mathrm{mmol} / \mathrm{L}$ in the control group.

\section{Independent Samples Test}

\begin{tabular}{|c|c|c|c|c|c|c|}
\hline & \multicolumn{2}{|c|}{\begin{tabular}{|c|} 
Levene's \\
Test for \\
Equality of \\
Variances \\
\end{tabular}} & \multicolumn{3}{|c|}{$\begin{array}{c}\text { T Test for } \\
\text { Equality of Means }\end{array}$} \\
\hline & & $\mathbf{F}$ & Sig & $\mathbf{t}$ & df & $\begin{array}{c}P \\
\text { value }\end{array}$ \\
\hline \multirow{2}{*}{$\begin{array}{l}\text { Serum } \\
\text { homo- } \\
\text { cysteine } \\
\text { level }\end{array}$} & $\begin{array}{c}\text { Equal Variances } \\
\text { Assumed }\end{array}$ & 10.629 & 0.002 & 3.726 & 58 & $<0.001$ \\
\hline & $\begin{array}{l}\text { Equal Variances } \\
\text { not Assumed }\end{array}$ & & & 4.925 & & $<0.001$ \\
\hline
\end{tabular}

\section{Chi-Square Test}

\begin{tabular}{|c|c|c|c|}
\hline & Value & df & P value \\
\hline Pearson Chi-square & 19.394 & 1 & $<0.001$ \\
\hline Continuity correction & 17.045 & 1 & $<0.001$ \\
\hline Likelihood ratio & 20.681 & 1 & $<0.001$ \\
\hline Number of valid cases & 60 & & \\
\hline
\end{tabular}

Using independent sample test and Chi-square test, it was deducted that a significant correlation exists between high serum homocysteine levels and the risk of developing premature coronary artery disease.

\section{Risk Factor Profile for IHD}

\begin{tabular}{|c|c|c|c|}
\hline & Risk Factor & Cases (n= 40) & $\begin{array}{c}\text { Controls } \\
(\mathbf{n = 2 0 )}\end{array}$ \\
\hline 1 & Male Sex & $35(87.5 \%)$ & $18(90 \%)$ \\
\hline 2 & Hypertension & $3(7.5 \%)$ & $6(30 \%)$ \\
\hline 3 & Diabetes Mellitus & $7(17.5 \%)$ & $2(10 \%)$ \\
\hline 4 & Smoking & $10(25 \%)$ & $12(60 \%)$ \\
\hline 5 & Alcohol & $7(17.5 \%)$ & $9(45 \%)$ \\
\hline 6 & Type A Personality & $18(45 \%)$ & $10(50 \%)$ \\
\hline 7 & Stress & $9(22.5 \%)$ & $3(15 \%)$ \\
\hline 8 & Family H/O IHD & $4(10 \%)$ & $5(25 \%)$ \\
\hline 9 & Dyslipidaemia & & \\
\hline & a) Hypercholeste & $11(27.5 \%)$ & $7(35 \%)$ \\
\hline & b) $\uparrow$ Triglyceriales & $9(22.5 \%)$ & $5(25 \%)$ \\
\hline
\end{tabular}

\begin{tabular}{|r|rr|c|c|}
\hline & c) $\uparrow$ VLDL & $0(0 \%)$ & $0(0 \%)$ \\
\hline & d) $\downarrow$ HDL & $16(40 \%)$ & $7(35 \%)$ \\
\hline & e) $\uparrow$ LDL & $14(30 \%)$ & $12(60 \%)$ \\
\hline 10 & $\uparrow$ Homocysteine Level & $30(75 \%)$ & $3(15 \%)$ \\
\hline
\end{tabular}

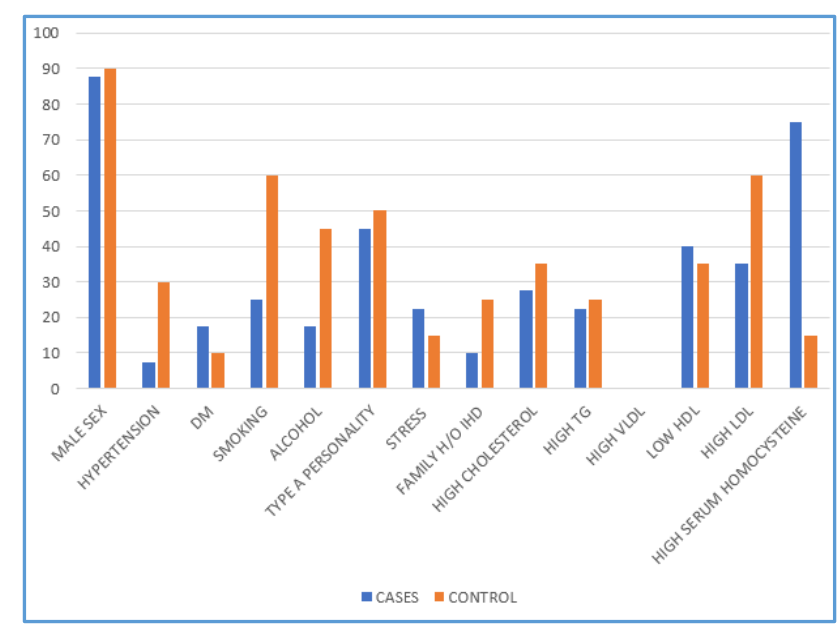

Risk Factor Profile for IHD (Percentage)

Male sex was found to be the most common risk factor among cases studied (87.5\%) followed closely by hyperhomocysteinaemia (75\%).

Only $17.5 \%$ of cases were Diabetics, $7.5 \%$ were hypertensives and $25 \%$ were smokers.

In contrast $60 \%$ of controls were smokers, $30 \%$ were hypertensives and $10 \%$ were diabetics.

$10 \%$ of all cases had family history of IHD.

\begin{tabular}{|c|c|c|}
\hline & Factor & P value \\
\hline 1 & Gender & 0.571 \\
\hline 2 & Age & 0.657 \\
\hline 3 & BMI & 0.236 \\
\hline 4 & Smoking & 0.015 \\
\hline 5 & Alcohol & 0.026 \\
\hline 6 & Socioeconomic Status & 0.012 \\
\hline 7 & Personality Type & 0.847 \\
\hline 8 & Lifestyle & 0.080 \\
\hline 9 & Diet & 0.030 \\
\hline 10 & Family H/O IHD & 0.006 \\
\hline 11 & Lipids & 0.193 \\
\hline 12 & DM & 0.259 \\
\hline 13 & Hypertension & 0.266 \\
\hline 14 & Homocysteine & $<0.001$ \\
\hline
\end{tabular}

Pearson's Chi-square Tests.

\section{Logistic Regression Table with Grouping}

\begin{tabular}{|c|c|c|c|c|}
\hline & $\begin{array}{c}\text { Independent } \\
\text { Variable }\end{array}$ & $\begin{array}{c}\boldsymbol{\beta} \\
\text { Coefficient }\end{array}$ & P value & $\begin{array}{c}\text { Odds } \\
\text { Ratio }\end{array}$ \\
\hline 1 & Smoking & 1.599 & 0.109 & 4.949 \\
\hline 2 & Alcohol & 0.695 & 0.525 & 1.906 \\
\hline 3 & HDL & 0.019 & 0.933 & 1.014 \\
\hline 4 & Serum Homocysteine & 3.331 & $<0.001$ & 27.968 \\
\hline 5 & Symptom Duration & 0.052 & 0.146 & 1.053 \\
\hline 6 & LDL & 1.226 & 0.166 & 0.293 \\
\hline
\end{tabular}

In a multiple logistic regression analysis with IHD as the dependent variable, significant correlation was seen with serum homocysteine level with odds ratio of 27.968 . 
Homocysteine Levels in other Risk Factor Groups

\begin{tabular}{|c|c|c|c|c|c|c|}
\hline & \multicolumn{4}{|c|}{ Serum Homocysteine Level } \\
\hline & & & \multicolumn{2}{|c|}{ Cases } & \multicolumn{2}{|c|}{ Controls } \\
\hline & & & High & Normal & High & Normal \\
\hline 1 & BMI & $\begin{array}{c}\text { Over } \\
\text { weight }\end{array}$ & $\begin{array}{c}5 \\
(62.5 \%)\end{array}$ & $\begin{array}{c}3 \\
(37.5 \%)\end{array}$ & $0(0 \%)$ & $\begin{array}{c}4 \\
(71.42 \%)\end{array}$ \\
\hline 2 & Hypertension & & $\begin{array}{c}4 \\
(57.14 \%)\end{array}$ & $\begin{array}{c}3 \\
(42.86 \%)\end{array}$ & $\begin{array}{c}1 \\
(16.66 \%)\end{array}$ & $\begin{array}{c}5 \\
(71.42 \%)\end{array}$ \\
\hline 3 & $\begin{array}{l}\text { Diabetes } \\
\text { Mellitus }\end{array}$ & & $\begin{array}{c}4 \\
(57.14 \%)\end{array}$ & $\begin{array}{c}3 \\
(42.86 \%)\end{array}$ & $0(0 \%)$ & $\begin{array}{c}2 \\
(100 \%)\end{array}$ \\
\hline 4 & Smoking & & $\begin{array}{c}10 \\
(100 \%)\end{array}$ & $0(0 \%)$ & $\begin{array}{c}1 \\
(8.33 \%)\end{array}$ & $\begin{array}{c}11 \\
(91.66 \%)\end{array}$ \\
\hline 5 & Alcohol & & $\begin{array}{c}5 \\
(71.42 \%)\end{array}$ & $\begin{array}{c}2 \\
(28.57 \%)\end{array}$ & $\begin{array}{c}1 \\
(11.1 \%)\end{array}$ & $\begin{array}{c}8 \\
(88.89 \%)\end{array}$ \\
\hline \multirow{3}{*}{6} & \multirow{3}{*}{ Social Class } & High & $\begin{array}{c}2 \\
(100 \%)\end{array}$ & $0(0 \%)$ & $0(0 \%)$ & $\begin{array}{c}5 \\
(100 \%)\end{array}$ \\
\hline & & Middle & $\begin{array}{c}27 \\
(77.14 \%) \\
\end{array}$ & $\begin{array}{c}8 \\
(22.86 \%)\end{array}$ & \begin{tabular}{|c|}
3 \\
$(23.07 \%)$ \\
\end{tabular} & $\begin{array}{c}10 \\
(76.92 \%) \\
\end{array}$ \\
\hline & & Low & \begin{tabular}{|c|}
3 \\
$(100 \%)$ \\
\end{tabular} & $0(0 \%)$ & $0(0 \%)$ & $\begin{array}{c}2 \\
(100 \%)\end{array}$ \\
\hline \multirow{3}{*}{7} & \multirow{3}{*}{$\begin{array}{c}\text { Personality } \\
\text { Type }\end{array}$} & A & \begin{tabular}{c|c}
16 \\
$(88.89 \%)$
\end{tabular} & $\begin{array}{c}2 \\
(11.11 \%) \\
\end{array}$ & $\begin{array}{c}2 \\
(25 \%) \\
\end{array}$ & $\begin{array}{c}6 \\
(75 \%) \\
\end{array}$ \\
\hline & & B & $\begin{array}{c}11 \\
(73.33 \%) \\
\end{array}$ & $\begin{array}{c}4 \\
(26.67 \%)\end{array}$ & $\begin{array}{c}0 \\
(0 \%)\end{array}$ & $\begin{array}{c}15 \\
(100 \%)\end{array}$ \\
\hline & & $\mathrm{C}$ & $\begin{array}{c}4 \\
(57.14 \%)\end{array}$ & $\begin{array}{c}3 \\
(42.86 \%)\end{array}$ & $\begin{array}{c}1 \\
(14.29 \%)\end{array}$ & $\begin{array}{c}6 \\
(85.71 \%)\end{array}$ \\
\hline \multirow{3}{*}{8} & \multirow{3}{*}{$\begin{array}{l}\text { Lifestyle/ } \\
\text { Stress }\end{array}$} & Heavy & $\begin{array}{c}8 \\
(88.89 \%)\end{array}$ & $\begin{array}{c}1 \\
(11.11 \%)\end{array}$ & $\begin{array}{c}1 \\
(33.33 \%)\end{array}$ & $\begin{array}{c}2 \\
(66.67 \%)\end{array}$ \\
\hline & & Moderate & $\begin{array}{c}16 \\
(66.67 \%)\end{array}$ & $\begin{array}{c}8 \\
(33.33 \%)\end{array}$ & $\begin{array}{c}2 \\
(16.67 \%)\end{array}$ & $\begin{array}{c}12 \\
(83.33 \%)\end{array}$ \\
\hline & & Sedentary & \begin{tabular}{|c|}
7 \\
$(100 \%)$ \\
\end{tabular} & $0(0 \%)$ & $0(0 \%)$ & $\begin{array}{c}3 \\
(100 \%)\end{array}$ \\
\hline \multirow{2}{*}{9} & \multirow[b]{2}{*}{ Diet } & Veg & $\begin{array}{c}5 \\
(83.33 \%)\end{array}$ & $\begin{array}{c}1 \\
(16.67 \%)\end{array}$ & $0(0 \%)$ & $\begin{array}{c}2 \\
(100 \%)\end{array}$ \\
\hline & & Mixed & $\begin{array}{c}25 \\
(73.52 \%)\end{array}$ & $\begin{array}{c}9 \\
(26.47 \%)\end{array}$ & $\begin{array}{c}3 \\
(16.67 \%)\end{array}$ & $\begin{array}{c}15 \\
(83.33 \%)\end{array}$ \\
\hline 1 & $\begin{array}{l}\text { Dyslipid- } \\
\text { aemia }\end{array}$ & & $\begin{array}{c}18 \\
(78.26 \%)\end{array}$ & $\begin{array}{c}5 \\
(21.73 \%)\end{array}$ & $\begin{array}{c}3 \\
(21.43 \%)\end{array}$ & $\begin{array}{c}11 \\
(78.57 \%)\end{array}$ \\
\hline
\end{tabular}
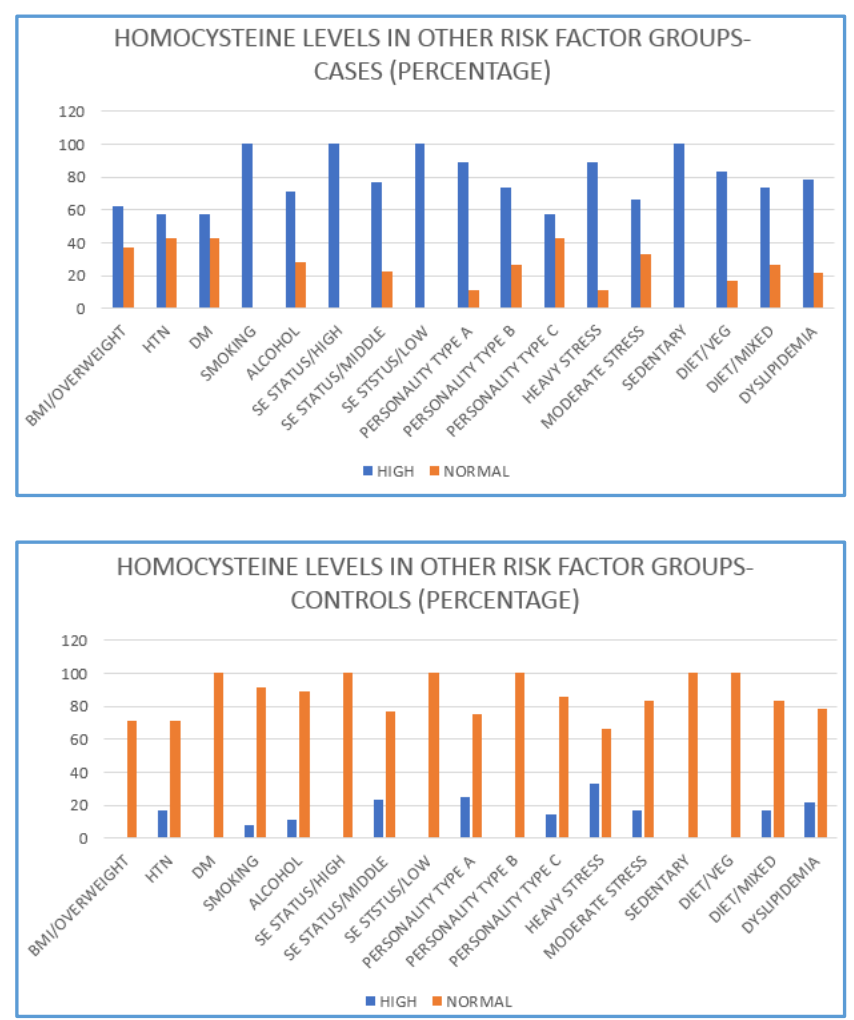

Another interesting observation was that hyperhomocysteinaemia was noted in majority of cases who were obese or hypertensive, diabetic, smokers and those with dyslipidaemias in comparison with controls.

\section{DISCUSSION}

In this observational case control study, 60 patients were recruited. 40 patients with ACS formed case group and 20 patients with non-cardiac chest pain formed control group. The principal finding of this study is the observation of hyperhomocysteinaemia in $75 \%$ of patients with early onset coronary artery disease as compared to $15 \%$ among the controls.

The unadjusted odds ratio among the patients with hyperhomocysteinaemia was 27.968, which were much higher than those for patients with other risk factors such as smoking, alcohol, dyslipidaemias, DM and hypertension.

A possible relation between hyperhomocysteinaemia and coronary artery disease was first suggested by Wilcken and Wilcken in 1976.[17]

The high and statistically significant plasma homocysteine levels in acute coronary syndromes are similar to the results in other Indian studies such as by A Puri and OK Gupta et al, where Hyperhomocysteinaemia had odds ratio of 6.05 compared to conventional risk factors like hypertension, smoking, diabetes and family history using multivariate logistic regression for statistical analysis.[18]

The odds ratio obtained in our study of young Goan population was much higher compared to the other studies. This could be possible due to different dietary habits in Goans. Though in the study, dietary habits were classified into mixed and vegetarians, non-vegetarian Goans consume very limited green leafy vegetables which is rich source of folate and the diet is predominantly composed of rice, fish and meat. Unfortunately, in our study we were unable to carry out measurements of folate, Vitamin B12 or pyridoxine due to financial constraints.

Also, in this study we only measured serum homocysteine level at admission prior to any medical intervention, irrespective of the fasting state. Fasting state homocysteine levels are lower than post methionine load.

Only patients presenting with ACS were included in our study. Hence, the higher mean homocysteine levels we have obtained compared to the other studies could possibly be explained by advanced coronary atherosclerotic process in these patients at presentation.

Again, a relatively small sample size could be a limiting factor in these differences in results observed.

Boushey et al reported a meta-analysis of 27 observational studies including about 4000 patients,[19] which concluded that raised homocysteine was associated with an increased risk of fatal and non-fatal atherosclerotic CVD (Odds ratio 1.7). It was estimated that about $10 \%$ of coronary artery disease in general population might be attributed to homocysteine. Since then there have been over 40 more case-control studies, most of them supporting the conclusions of Boushey et al. Graham et al[20] in the large European Collaborative Study (ECAP) showed mean homocysteine levels of $11.25 \mu \mathrm{mol} / \mathrm{L}$, which was significantly higher than controls. 
Reduced intake of Vitamin B12 has been reported in Indians and cooking may further destroy folate content. This may account for higher homocysteine levels in Indians.

A study by Schaffer et al in 2014 observed a strong association between homocysteine level and CAD with odds ratio of 1.18 and $p$ value $<0.001$.[21]

In this study, the mean levels of homocysteine in patients $(20.32 \pm 8.62)$ were almost twice that of the controls $(12.92 \pm$ 2.83), $75 \%$ cases had hyperhomocysteinaemia compared to $15 \%$ of controls. This is comparable to a similar study by A Puri and OK Gupta et al, wherein the mean homocysteine levels in patients was found to be $(27.80 \pm 13.11)$ and in controls (13.22 \pm 7.36$) ; 73 \%$ patients and about $27 \%$ control had higher than normal homocysteine levels.[18]

Our study findings were in contrast with some studies such as by R Deepa and K Velmurugan et al in Chennai, where they found absence of association between serum homocysteine levels and CAD in South Indian Males.[22]

In some studies done in India by Gheye et al (1999) and Sastry et al (2001), the mean homocysteine levels were higher compared to similar western studies. One possible reason for this discrepancy may be because of differences in dietary habits. Reduced intake of Vitamin B12 and folate may result from prolonged cooking of vegetables, which is a common practice in Indian households. Dietary deficiencies may also result from chronic intestinal infections, again common in India. In the present study, the mean age of patients was $38.25 \pm 5.35$ years. In the Indian sub-continent, CAD occurs about a decade earlier as compared to the western world.

The sex distribution in this study was $87.5 \%$ males and $12.5 \%$ females. The study was predominantly male oriented, as CAD affects young males more severely and commonly than females. This result is similar to a study done by Laxman et al among South Asians, where it was found that coronary artery disease is 2.5 times more common in men than in women.

In our study, the cases had 10 smokers and all had high homocysteine levels. Association of smoking with increased homocysteine levels was first shown by Berg and Mark et al in 1997. They also concluded that smokers with higher homocysteine levels $>12 \mu \mathrm{mol} / \mathrm{L}$ are at $>12$-fold risk for CAD.[23]

Dyslipidaemia was seen in $57.5 \%$ of the patients in our study population. Elevated serum cholesterol is causally associated with increased risk of CAD. Specifically, a $10 \%$ increase in serum cholesterol is associated with a $20-30 \%$ increased risk of $\mathrm{CAD}$ and elevations earlier in life may be associated with higher risk of CAD.

A low HDL and high triglyceride along with LDL can occur alone or in combination and multiply the risk of CAD.

In our study, it was noted that dyslipidaemic patients had higher homocysteine levels than the patients with normal lipid profile. In contrast, SN Pandey et al in 2006 did not find any co-relation between homocysteine and hypertriglyceridaemia in a study on women.

Increased incidence of hypercholesterolaemia in the Goan population may be related to the diet consumed by most of the people in Goa and neighbouring states, which includes the staple use of coconut which is rich in saturated fat.
Only $17.5 \%$ of the patients in the study population were diabetics. All detected during the current admission. However, $57.14 \%$ of the diabetes in study group had higher than normal Homocysteine levels. Our study population is small to allow analysis to determine independent role of these variables. Hoffman et al reported that hyperhomocysteinaemia is more common in type I diabetics with nephropathy. However, contrasting findings were noted by $\mathrm{R}$ Deepa et al 2001, whose data showed that there was no significant increase of homocysteine levels in diabetics per se or in diabetic patients with CAD. They attributed this finding to the fact that the body mass index was similar among the study groups.

Our study has thus differed from the results of similar smaller Indian studies, which showed not much difference in plasma homocysteine levels between cases and controls.

Ideally to draw definite conclusions regarding homocysteine as a coronary risk factor, a prospective cohort study with adequate sample size taking into account the high degree of variance in homocysteine levels in our populations is required. Further, the importance of nutritional and genetic factors needs to be addressed. This study was limited by the fact that other determinants of plasma homocysteine like Folic acid, pyridoxine and Vitamin B12 levels could not be measured and assessed due to financial constraints.

\section{CONCLUSION}

Our study concluded that hyperhomocysteinaemia is a strong risk factor for premature CAD in young Goan patients who presented with acute coronary syndrome. The study also deducted that smoking, dyslipidaemia, diabetes mellitus and hypertension are associated with hyperhomocysteinaemia.

\section{REFERENCES}

[1] Ganguly P, Alam SF. Role of Homocysteine in development of cardiovascular disease. Nutrition Journal 2015;14:6.

[2] Guo H, Chi J, Xing Y, et al. Influence of folic acid on plasma Homocysteine levels \& arterial endothelial function in patients with unstable angina. Indian J Med Res 2009;129(3):279-84.

[3] Faeh D, Chiolero A, Paccaud F. Homocysteine as a risk factor for cardiovascular disease: Should we (still) worry about it? Swiss Med Wkly 2006;136(4748):745-56.

[4] Ueland PM. Homocysteine species as components of plasma redox thiol status. Clin Chem 1995;41(3):34042.

[5] Seshadri N, Robinson K. Homocysteine, B Vitamins and coronary artery disease. Medical Clinics of North America 2000;84(1):215-37.

[6] Finkelstein JD. The metabolism of Homocysteine: pathways and regulation. Eur J Pediatr 1998;157(Suppl 2):S40-S4.

[7] Curro M, Gugliandolo A, Gangemi C, et al. Toxic effects of mildly elevated Homocysteine concentrations in neuronal-like cells. Neurochem Res 2014;39(8):148595.

[8] Hankey GJ, Eikelboom JW. Homocysteine and vascular disease. Lancet 1999;354(9176):407-13. 
[9] Selhub J, Jacques PF, Wilson PW, et al. Vitamin status and intake as primary determinants of Homocysteinemia in an elderly population. JAMA 1993:270(22):2693-8.

[10] Nygard O, Refsum H, Ueland PM, et al. Major lifestyle determinants of plasma total Homocysteine distribution: the Hordaland Homocysteine Study. Am J Clin Nutr 1998;67(2):263-70.

[11] Brattstrom L, Israelson B, Norrving B, et al. Impaired Homocysteine metabolism in early onset Cerebral and peripheral occlusive arterial disease. Effects of pyridoxine and Folic acid treatment. Atherosclerosis 1990;81(1):51-60.

[12] Wollesen F, Brattstrom L, Refsum H, et al. Plasma Total Homocysteine and cysteine in relation to glomerular filtration rate in diabetes mellitus. Kidney Int 1999;55(3):1028-35.

[13] Zhang S, Bai YY, Luo LM, et al. Association between serum Homocysteine and arterial stiffness in elderly: a community-based study. J Geriatr Cardiol 2014;11(1):32-8.

[14] Pang X, Liu J, Zhao J, et al. Homocysteine induces the expression of $\mathrm{C}$ - reactive protein via NMDAr-ROSMAPK-NF- $\kappa B$ signal pathway in rat vascular smooth muscle cells. Atherosclerosis 2014;236(1):73-81.

[15] Krishnaswamy K, Lakshmi AV. Role of Nutritional supplementation in reducing the levels of Homocysteine. J Assoc Physicians India 2002;Suppl 50:36-42.

[16] Malinow MR, Duell PB, Hess DL, et al. Reduction of plasma Homocyst(e)ine Levels by breakfast cereal fortified with folic acid in patients with coronary heart disease. N Eng J Med 1998;338(15):1009-15.
[17] Wilcken DE, Wilcken B. The pathogenesis of coronary artery disease: a possible role for methionine metabolism. J Clin Invest 1976;57(4):1079-82.

[18] Puri A, Gupta OK, Dwivedi RN, et al. Homocysteine and lipid levels in young patients with coronary artery disease. J Aaaoc Physicians India 2003;51:681-5.

[19] Boushey CJ, Beresford SA, Omenn GS, et al. A quantitative assessment of plasma Homocysteine as a risk factor for vascular disease: probable benefits of increasing folic acid intakes. JAMA 1995;274(13):1049-57.

[20] Graham IM, Daly LE, Refsum HM, et al. Plasma Homocysteine as a risk factor for vascular disease: The European Concerted Action Project. JAMA 1997;277(22):1775-81.

[21] Schaffer A, Verdoia M, Casseti E, et al. Relationship between Homocysteine and coronary artery disease. Results from a large prospective cohort study. Thrombosis Research 2014;134(2):288-93.

[22] Deepa R, Velmurugan K, Saravanan G, et al. Absence of association between serum Homocysteine and coronary artery disease in south Indian males. Indian Heart J 2001;53(1):44-7.

[23] Bergmark C, Mansoor MA, Svardal A, et al. Redox status plasma Homocysteine and related aminothiols in smoking and non-smoking young adults. Clinical Chemistry 1997;43(10):1997-9. 